\title{
COMMENT
}

\section{Children and the American Rescue Plan: countering COVID-19 vaccine hesitancy during a global pandemic}

\author{
Shetal Shah ${ }^{1}$ \\ Pediatric Research (2021) 90:237-239; https://doi.org/10.1038/s41390-021-01590-8
}

This March, we commemorated the 1-year anniversary of the novel coronavirus, COVID-19's, official United States (US) designation as a national emergency. Over the past year, lockdowns, quarantines, mask mandates, temperature screening, "ZOOM"-ing, and social distancing became part of our daily vocabularies. As of this writing, there have been 128 million global cases and 2.6 million deaths. ${ }^{1}$ In the US, we are approaching 31 million cases and 551,000 fatalities. ${ }^{1}$ Roughly 3.4 million cases, or $>1$ in 10 in the US, have been in children. ${ }^{2}$ In this issue, Zhou et al. analyze 52 published case reports and series comprising 203 children to better identify risk factors for severe disease among children, with various degrees of illness upon initial presentation. ${ }^{3}$ The authors have provided preliminary data that will be valuable to frontline physicians attempting to triage children who may develop critical COVID-19 illness, and if replicated, may allow for better allocation of resources within pediatric departments and children's hospitals-information that appears even more important in the context of past reported hospital-bed shortages that occurred during the peak of the pandemic. ${ }^{4}$

While knowledge of COVID-19 has increased exponentially in the past year, the article highlights the need to better understand-not only the unique pathophysiology of the disease in children, but also the critical public health role children will play in preventing disease. This is especially true as over 577 million doses of vaccine have been administered as part of the global rollout of COVID-19 immunizations, but thus far only in adults. ${ }^{5}$

\section{BURDEN OF COVID-19}

Overall, children seem to be relatively spared direct biological consequences of the illness from COVID-19. Chronic obstructive pulmonary disease, diabetes, and obesity - the most common risk factors for serious COVID-19 illness are more common adult conditions. ${ }^{6,7}$ Children under 10 years represent $\sim 1 \%$ of COVID cases. ${ }^{8,9}$ Pediatric patients ( $0-17$ years), per the Centers for Disease Control and Prevention (CDC) comprise only 331 of US COVID-19 deaths. ${ }^{10}$ Compared to $5-17$-year olds, risk of death is between $1100 \times-7900 \times$ higher for adults older than 65 years. ${ }^{11}$ Clinical disease is also less severe in children than in adults younger than 65 years. ${ }^{12,13}$ Rates vary worldwide, but US data demonstrated a hospitalization rate of 17 per 100,000 , with rates $40 \times-80 \times$ higher in adults over 85 years. ${ }^{11,12,14-16}$ However, as Zhou notes in this paper, within the pediatric population, infant and young children $<4$ years are more likely to be severely ill compared to older children.,17 Children under 1 year of age, or with underlying chronic disease are unsurprisingly, at even higher risk. ${ }^{16,18}$ Of course, these data also do not capture the psychosocial ills from the pandemic created by isolation from family, friends, and loss of in-person school.

State-reported data indicate all children represent $\sim 13 \%$ of all COVID-19 cases reported. ${ }^{2}$ However, in Italy and Canada, only $\sim 2 \%$ of all clinical cases are in children, suggesting a sizeable asymptomatic burden of virus in children. ${ }^{16,19,20}$ This has created robust debate about this variation and the potential role of mandatory childhood COVID-19 vaccination in children, especially when adult immunization rates of $\sim 70 \%$ may confer herd immunity. ${ }^{20,21}$ The ability to achieve such high rates of adult vaccination will be hindered by high rates of vaccination hesitancy. ${ }^{22}$

In adults, the three vaccines authorized in the US exhibit 66-95\% efficacy, yet there remain concerns about side effects, need for vaccination, and the rate at which the vaccines were developed. ${ }^{23}$ Globally, adult hesitancy rates range from $10-45 \% .^{21}$ In the US, rates of hesitancy (reported in February 2021) toward COVID-19 immunization averaged 35\%-with disparities in vaccine acceptance based on race and political affiliation. $^{24}$

\section{VACCINATION HESITANCY AND THE AMERICAN RESCUE PLAN}

Countering vaccine hesitancy in adults, despite their high burden of COVID-19 disease will require both patient and population-based interventions. Informed public policy, based on science and evidence has a strong role at both levels. Even prior to COVID-19, vaccine hesitancy, including among children, was an epidemic, declared by the World Health Organization as a "top 10" threat to global health in $2019 .{ }^{22}$ It is likely that personal counseling provided by an individual's physician may be the most effective means of combatting skepticism, regarding COVID-19 vaccines. ${ }^{25-28}$ A person's primary physician, data shows, holds a large reservoir of public trust, and may be the most influential in counseling hesitant patients toward immunization. However individual vaccine counseling sessions for up to $1 / 3$ of the US population incurs significant cost. The recently passed American Rescue Plan has allocated \$1 billion to the $C D C$ to increase vaccine confidence. Yet given the allocation to a public health agency, use of the funds to pay for direct physician counseling, while potentially most effective, is unlikely. Further, that patient vaccine counseling takes time, and is poorly reimbursed, which will likely also hamper efforts to attain high adult immunization rates. ${ }^{29-31}$ The federal government did increase payment for COVID-19 vaccine administration to $100 \%$

${ }^{1}$ https://www.nature.com/PediatrRes

Correspondence: Shetal Shah (shahs2@wcmc.com)

Received: 13 April 2021 Accepted: 10 May 2021

Published online: 25 May 2021 
of the Federal Medical Assistance Percentage within Medicaid; however, pediatricians will only realize this financial incentive upon vaccination, meaning counseling that does not result in a caregiver or child obtaining immunization will remain poorly compensated. It is also unclear what role pediatricians will play in immunizing caregivers of eligible patients, and what priority pediatric practices will be given regarding vaccine allocation. These issues must be considered to better operationalize COVID-10 vaccination.

Most likely, American Rescue Plan funds will be allotted toward a robust public health campaign encouraging immunization. However the effectiveness of traditional public health campaigns is mixed. Anti-tobacco campaigns have been shown to be both cost-effective and encourage reduced tobacco use. ${ }^{32-34}$ Comparatively, immunization campaigns have only been moderately successful, increasing vaccination rates in only $11 \%$ in one study. ${ }^{35,36}$ As public health messaging is developed and implemented, novel approaches should be considered. Specifically, effectiveness may require a stronger pivot to social media, where vaccine hesitancy myths are perpetuated and anti-vaxxers thrive. ${ }^{37}$ Though social media organizations have curtailed availability and monetization of anti-vaccine content, exposure to negative social media content regarding immunization is associated with a greater refusal. ${ }^{38}$ Lessons from social media content regarding human papilloma virus vaccination are instructive. ${ }^{37}$ Since the anti-vax demographic displays less trust in government, pharmaceutical and medical authoritiesexpert content may not be influential. ${ }^{39}$ Use of well-respected charitable organizations and age-appropriate "influencers" sharing personal reasons for vaccination may be more effective.

\section{THE NEED FOR A SPECIAL FOCUS ON CHILDREN AND CONGRESSIONAL HEARINGS ON CHILDREN AND COVID-19 VACCINATION}

There is evolving consensus on the need to vaccinate children against COVID-19. ${ }^{20,40}$ As reservoirs of disease, immunizing children may be a required public health strategy. Children are not often not direct vectors of disease, implicated as index cases in $0.5-10 \%$ of infectious in households. ${ }^{41-44}$ Yet since they exhibit higher viral loads, targeting children for immunization may reduce the amount of circulating disease and secondarily protect adults - a strategy that has been effective in mitigating influenza disease. ${ }^{20,45,46}$ Further, immunization of children is expected to reduce the burden of the COVID-associated multisystem inflammatory system in children. ${ }^{47,48}$ Articulating the need for vaccinating children when they are not frequently severely ill will be difficult, particularly to a skeptical public.

As of this writing, two vaccine preparations have completed enrollment in children 12 years and older, with studies in children 6 months-12 years currently enrolling. ${ }^{49,50}$ But the ideal approaches to raise vaccination rates in children if indicated, is not known. Further, blueprints to counter hesitancy in adults may not be applicable in motivating them to permit vaccination of their children, where decision-making can be vastly different. ${ }^{51,52}$ To offer maximal transparency regarding the need for potential childhood COVID-19 immunization, and openly review the safety, and efficacy data-and most importantly the limits, of ongoing trials, congressional hearings on COVID-19 vaccination and children should be a high priority. These hearings would play an important role in establishing trust about a relatively new vaccine, spotlight what is known about the role of children in COVID-19 transmission, openly acknowledge what is unknown and requires further inquiry-highlighting potential research priorities. This information would also be timely as schools wrestle with challenge to reopen amidst changing $\mathrm{CDC}$ guidelines, disease variants, and varying public opinion about potential COVID vaccine mandates for children should the vaccines prove safe and effective in this population. ${ }^{53}$
A year into the pandemic, Zhou et al.'s work reminds us that children were not unscathed by this disease. Addressing the complexities of vaccination will require thoughtful and open policy, individual physician-patient advocacy and collective understanding.

\section{ADDITIONAL INFORMATION}

Competing interests: The author declares no competing interests.

Publisher's note Springer Nature remains neutral with regard to jurisdictional claims in published maps and institutional affiliations.

\section{REFERENCES}

1. Coronavirus Resource Center. COVID-19 Dashboard by the Center for Systems Science and Engineering (CSSE) at Johns Hopkins University https://coronavirus. jhu.edu/map.html (2021).

2. American Academy of Pediatrics. Children and COVID-19: state-level data report https://services.aap.org/en/pages/2019-novel-coronavirus-covid-19-infections/ children-and-covid-19-state-level-data-report/ (2021).

3. Zhou, B. et al. Risk Profiles of Severe Illness in Children with COVID-19: A MetaAnalysis of Individual Patients Pediatr. Res. (2021, included in this issue).

4. Murray, C. J. L. Forecasting COVID-19 impact on hospital bed-days, ICU-days, ventilator-days and deaths by US state in the next 4 months. Institute for Health Metrics and Evaluation https://www.medrxiv.org/content/10.1101/ 2020.03.27.20043752v1 (2020).

5. Coronavirus (COVID-19) Vaccinations. Statistics and research. Our World in data https://ourworldindata.org/covid-vaccinations?country= OWID_WRL\#how-manycovid-19-vaccination-doses-have-been-administered (2021).

6. Velavan, T. P., Pollard, A. J. \& Kremsner, P. G. Herd Immunity and vaccination of children for COVID-19. Int. J. Infect. Dis. 98, 14-15 (2020).

7. Velavan, T. P. \& Meyer, C. G. Mild versus severe COVID-19: laboratory markers. Int. J. Infect. Dis. 95, 304-307 (2020).

8. Kelvin, A. A. \& Halperin, S. COVID-19 in children: the link in the transmission chain. Lancet 20, 633-634 (2020).

9. Wu, Z. \& McGoogan, J. M. Characteristics of and important lessons from the coronavirus disease 2019 (COVID-19) outbreak in China: summary of a report of 72314 cases from the Chinese center for disease control and prevention. JAMA 323, 1239-1242 (2020).

10. Centers for Disease Control and Prevention. COVID data tracker https://covid.cdc. gov/covid-data-tracker/\#demographics (2021).

11. Centers for Disease Control and Prevention. COVID-19 https://www.cdc.gov/ coronavirus/2019-ncov/covid-data/investigations-discovery/hospitalization-deathby-age.html (2021).

12. Dong, Y. et al. Epidemiology of COVID-19 among children in China. Pediatrics 145 , e20200702 (2020).

13. Kim, J. et al. Role of children in household transmission of COVID-19. Arch Dis Child https://doi.org/10.1136/archdischild-2020-319910 (2020).

14. Levin, Z., Choyke, K., Georgiou, A., Sen, S. \& Karaca-Mandic, P. Trends in pediatric hospitalizations for coronavirus disease 2019. JAMA Pediatr. https://doi.org/ 10.1001/jamapediatrics.2020.5535 (2021).

15. Choi, S. H., Kim, H. W., Kang, J. M., Kim, D. H. \& Cho, E. Y. Epidemiology and clinical features of coronavirus disease 2019 in children. Clin. Exp. Pediatr. 63, 125-132 (2020).

16. Bellino, S. et al. COVID-19 disease severity risk factors for pediatric patients in Italy. Pediatrics 146, e2020009399 (2020).

17. Li, Y., Guo, F., Cao, Y., Li, L. \& Guo, Y. Insight into COVID-2019 for pediatricians. Pediatr. Pulmonol. 55, E1-E4 (2020).

18. Mehta, N. S. et al. SARS-CoV-2 (COVID-19): what do we know about children? A systematic review. Clin. Infect. Dis. 71, 2469-2479 (2020).

19. Barton, M. et al. COVID-19 infection in children: estimating pediatric morbidity and mortality. Preprint at https://www.medrxiv.org/content/10.1101/ 2020.05.05.20091751v1.full.pdf (2020).

20. Plotkin, S. A. \& Levy, O. Considering mandatory vaccination of children for COVID-19. Pediatrics https://doi.org/10.1542/peds.2021-050531 (2021).

21. Giordano, G. et al. Modelling the COVID-19 epidemic and implementation of population-wide interventions in Italy. Nat. Med. 26, 855-860 (2020).

22. World Health Organization. Ten threats to global health in 2019 https://www. who.int/news-room/spotlight/ten-threats-to-global-health-in-2019 (2021).

23. United States Food and Drug Administration. FDA Issues emergency use authorization for third COVID-19 vaccine https://www.fda.gov/news-events/ press-announcements/fda-issues-emergency-use-authorization-third-covid-19vaccine (2021). 
24. Karpman, M., Kenney, G. M., Zuckerman, S., Gonzalez, D. \& Courtot, B. Confronting COVID-19 vaccine hesitancy among nonelderly adults. Robert Wood Johnson Foundation and Urban institute https://www.rwjf.org/en/library/research/2021/02/ confronting-covid-19-vaccine-hesitancy-among-nonelderly-adults.html (2021).

25. Henrikson, N. B. et al. Physician communication training and parental vaccine hesitancy: a randomized trial. Pediatrics 136, 70-79 (2015)

26. Lepere, K., Etsekson, N. \& Opel, D. J. Provider self-disclosure during the childhood vaccine discussion. Clin. Pediatr. 58, 691-695 (2019).

27. Shah, S., Brumberg, H. L. \& La Gamma, E. F. Applying lessons from vaccination hesitancy to address birth dose Vitamin $\mathrm{K}$ refusal: Where has the trust gone? Semin. Perinatol. 44, 151242 (2020).

28. Lundahl, B. \& Burke, B. L. The effectiveness and applicability of motivational interviewing: a practice-friendlyreview of four meta-analyses. J. Clin. Psychol. 65, 1232-1245 (2009).

29. Jacobson, R. M., St Sauver, J. L. \& Finney Rutten, L. J. Vaccine hesitancy. Mayo Clin. Proc. 90, 1562-1568 (2015).

30. Shah, S. Immunization issues in preterm infants: pertussis, influenza, and rotavirus. Neoreviews 15, e439-e448 (2014).

31. Opel, D. J. et al. Impact of childhood vaccine discussion format over time on immunization status. Acad. Pediatr. 18, 430-436 (2018).

32. Wakenfield, M. A., Loken, B. \& Hornik, R. C. Use of mass media campaigns to change health behavior. Lancet 376, 1261-1271 (2010).

33. Bala, M., Strzeszynski, L. \& Cahill, K. Mass media interventions for smoking cessation in adults. Cochrane Database Syst. Rev. 1, CD004704 (2008)

34. Wakefield, M. A. et al. Impact of tobacco control policies and mass media campaigns on monthly adult smoking prevalence. Am. J. Public Health 98, 1443-1450 (2008).

35. Randolph, W. \& Viswanath, K. Lessons learned from public health mass media campaigns: marketing health in a crowded media world. Annu. Rev. Public Health 25, 419-437 (2004)

36. Colgrove, J. Vaccine refusal revisited- the limits of public health persuasion and coercion. N. Engl. J. Med. 375, 1316-1317 (2016)

37. Ortiz, R. R., Smith, A. \& Coyne-Beasley, T. A systematic literature review to examine the potential for social media to impact HPV vaccine update and awareness, knowledge, and attitudes about HPV and HPV vaccination. Hum. Vaccin. Immunother. 15, 1465-1475 (2019).

38. Margolis, M. A., Brewer, N. T., Shah, P. D., Calo, W. A. \& Gilkey, M. B. Stories about HPV vaccine in social media, traditional media, and conversations. Prev. Med. 118, 251-256 (2019)
39. Dubé, E., Vivion, M. \& MacDonald, N. E. Vaccine hesitancy, vaccine refusal and the anti-vaccine movement: influence, impact and implications. Expert Rev. Vaccines 14, 99-117 (2015).

40. Cooper, D. M. et al. SARS-CoV-2 vaccine testing and trials in the pediatric population: biologic, ethical, resrach and implementation challenges. Pediatr. Res. https://doi.org/10.1038/s41390-021-01402-z (2021).

41. Posfay-Barbe, K. M. et al. COVID-19 in children and the dynamics of infection in families. Pediatrics 146, e20201576 (2020).

42. Lee, B. \& Raszka, W. V. COVID-19 transmission and children: the child is not to blame. Pediatrics 146, e2020004879 (2020).

43. Cai, J. et al. A case series of children with 2019 novel coronavirus infection: clinical and epidemiological features. Clin. Infect. Dis. https://doi.org/10.1093/cid/ciaa198 (2020).

44. Kim, J. et al. Role of children in household transmission of COVID-19. Arch. Dis. Child. https://doi.org/10.1136/archdischild-2020-319910 (2020).

45. King, J. C. et al. Effectiveness of school-based influenza vaccination. N. Engl. J. Med. 355, 2523-2532 (2006).

46. Weycker, D. et al. Population-wide benefits of routine vaccination of children against influenza. Vaccine 23, 1284-1293 (2005)

47. Chiotos, K. et al. Multisystem inflammatory syndrome in children during the coronavirus 2019 pandemic: a case series. J. Pediatr. Infect. Dis. Soc. 9, 393-398 (2020).

48. Feldstein, L. R. et al. Multisystem inflammatory syndrome in US children and adolescents. N. Engl. J. Med. 383, 334-346 (2020).

49. Moderna, T. X., Inc. A study to evaluate safety and effectiveness of mRNA-1273 vaccine in healthy children between 6 months of age and less than 12 years of age https://clinicaltrials.gov/ct2/show/study/NCT04796896 (2021).

50. BioNTech SE and Pfizer. Study to evaluate the safety, tolerability and immunogenicity of an RNA vaccine candidate against COVID-19 in healthy children $<12$ years of age. https://clinicaltrials.gov/ct2/show/NCT04816643 (2021).

51. Zhang, K. C. et al. Parental acceptability of COVID-19 vaccination for children under the age of 18 years: cross sectional online survey. JMIR Pediatr. Parent. $\mathbf{3}$, e24827 (2020).

52. Goldman, R. D. et al. Factors associated with parents' willingness to enroll their children in trials for COVID-19 vaccination. Hum. Vaccines Immunother. https://doi. org/10.1080/21645515.2020.1834325 (2020).

53. Centers for Disease Control and Prevention. Operating schools during COVID-19: CDC's considerations https://www.cdc.gov/coronavirus/2019-ncov/community/ schools-childcare/schools.html (2021). 